\title{
Myofilament function and body mass index
}

\author{
CONSTANZE BENING ${ }^{1,2}$, KHALED HAMOUDA $^{2}$, CHRISTOPH SCHIMMER $^{2}$ and RAINIER LEYH ${ }^{2}$ \\ ${ }^{1}$ Department of Cardiothoracic and Vascular Surgery, Johannes Gutenberg University, D-55122 Mainz; \\ ${ }^{2}$ Experimental Laboratory, Department of Cardiothoracic Surgery, University Hospital Würzburg, \\ D-97080 Würzburg, Germany
}

Received November 15, 2016; Accepted January 25, 2017

DOI: $10.3892 /$ br.2017.858

\begin{abstract}
Body mass is reported to influence myocardial performance. Recent studies have emphasised the importance of negative inotropic adipocyte-derived factors and their impact on cardiac contractile function. However, the underlying mechanisms remain unclear. We aimed to determine whether body mass impacts cardiac force development on the level of the contractile apparatus. We examined the influence of body mass index (BMI) (3 groups: group I $>25$, group II 25-30, group III $>30$ ) on the myocardial performance of skinned muscle fibres. Right atrial tissue preparations of 70 patients undergoing aortocoronary bypass operation (CABG, 48 patients, group a) and aortic valve replacement (AVR, 22 patients, group b) were obtained. The fibres were exposed to a gradual increase in the calcium concentration, and the force values were recorded. The statistical analysis was performed using Pearson's correlation ( $\mathrm{P}<0.05$ significant). A BMI $>30$ (group III) was associated with less force (mean force $1.58 \pm 0.1 \mathrm{mN}, \mathrm{P}=0.02$, max force $2.24 \pm 0.17 \mathrm{mN}, \mathrm{P}=0.02$ vs. group II (mean force $1.8 \pm 0.3 \mathrm{mN}$, $\mathrm{P}=0.04$, max force $2.59 \pm 0.2 \mathrm{mN}, \mathrm{P}=0.03$ ) and group I (mean force $1.8 \pm 0.1 \mathrm{mN}, \mathrm{P}=0,03$, max force $2.62 \pm 0.3 \mathrm{mN}, \mathrm{P}=0.03$ ). Dividing the groups in the post-surgical procedure, the impact of BMI on force development in group III was more intense in the CABG group compared to the AVR group: $2.0 \pm 0.2 \mathrm{mN}$ vs. $2.4 \pm 0.1 \mathrm{mN}, \mathrm{P}=0.04$. In accordance with the literature, a BMI $>30$ is associated with reduced force capacities. Additionally, the underlying cardiac disease may aggravate the impact of weight on cardiac force. Further studies are needed to evaluate the clinical relevance of this experimental observation and the potential consequences for the treatment of cardiac function.
\end{abstract}

Correspondence to: Dr Constanze Bening, Experimental Laboratory, Department of Cardiothoracic Surgery, University Hospital Würzburg, 6 Oberdürrbacher Street, D-97080 Würzburg, Germany

E-mail: constanze.bening@googlemail.com

Key words: obesity, myofilaments, skinned fibers, body mass index, contractility

\section{Introduction}

The obesity paradox describes the paradoxical relationship between obesity and mortality in specific populations, although obesity is a risk factor for diabetes type 2, hypertension, dyslipidemia and other cardiovascular diseases and has a negative impact on health outcomes (1). Obesity is assumed to also have an impact on myocardial function; however, although evidence exists, this has not been confirmed, as abdominal obesity induces insulin resistance, which may have a potent effect on myocardial function (2). Furthermore, cardiac function can be depressed, and the development of severe cardiomyopathy can be promoted (3). Similar to diabetic cardiomyopathy, obesity cardiomyopathy is characterised by reduced LV diastolic dysfunction, impaired diastolic LV longitudinal function and increased LV diastolic filling pressures (4). Furthermore, increased myocardial collagen content has been observed (4). However, although the relationship between obesity and heart failure is widely acknowledged, the pathophysiological mechanisms regarding how obesity affects cardiomyocytes remain unclear and have yet to be examined.

Different mechanisms affecting cardiomyocytes have been discussed: obesity as an increased hemodynamic load, which leads to ventricular remodelling and systolic dysfunction, due to prolonged left ventricular stress, or increased lipid accumulation into cardiac myocytes leading to cardiomyocyte apoptosis and dysfunction. Another proposed mechanism is the endocrine activity of adipose tissue, which releases a variety of peptides and proteins, which are shown to attenuate cardiomyocyte contraction $(5,6)$. Leptin, for example, has been shown to play a role in cardiovascular physiology and was observed to suppress cardiac contraction in high doses (7). Different studies have shown that adipose tissue exerts highly potent cardiodepressant activity, which could also have an acute effect on cardiomyocyte contraction $(5,6)$. This may be the missing link between heart failure and obesity, but it has not been proven.

Experimental evidence in accordance to the clinical 'entity' of obesity cardiomyopathy, which is described echocardiographically by slightly reduced diastolic LF function, increased diastolic filling pressures and higher myocardial collagen content, is hypothesised to affect myofilament function. The purpose of this study was therefore to examine the impact of different body mass index (BMI) stages on contractile apparatus. 


\section{Materials and methods}

Clinical setting. The experiments were carried out at the Experimental Laboratory of the Department of Cardiothoracic and Vascular Surgery, Johannes Gutenberg University (Mainz, Germany). The Ethics Committee of the Medical Association Rheinhessen approved the study. All the patients gave written consent to use intraoperative resected tissue for further research examination. The study was performed conforming to the declaration of Helsinki.

Patients collective. This was a prospective study with patients scheduled for elective cardiac surgery. A total of 70 patients undergoing cardiac surgery were included. The patients were divided into two groups according to the operative procedure of aortocoronary bypass grafting (CABG) or aortic valve replacement procedure (AVR). The AVR group consisted of 22 patients, and the CABG group consisted of 48 patients (Table I). We performed a classification according to the WHO classification of BMI into 3 groups: group I $>25$, group II 25-30, and group III $>30$.

Exclusion criteria. We excluded patients presenting as emergency cases, endocarditis, combined procedures (CABG and valve operations), operations on the ascending aorta and patients with clinical as well as echocardiographic signs of chronic or acute right or acute left heart failure.

\section{Experimental setting}

Skinned fibre preparation. The process of skinned fibre preparation has been described in detail elsewhere (8). Briefly, the fibres were collected in the operation room after resecting the right auricle. In the no-touch technique, the auricle was transferred in an ice-cooled vial $\left(4^{\circ} \mathrm{C}\right)$, filled with modified cardioplegic solution (Krebs-Henseleit solution, in $\mathrm{mmol} / \mathrm{l}$ : $118.07 \mathrm{NaCl}, 11.1 \mathrm{C}_{6} \mathrm{H}_{12} \mathrm{O}_{6}+\mathrm{H}_{2} \mathrm{O}, 4.7 \mathrm{KCL}, 25 \mathrm{NaHCO}_{3}$, 1.2 $\mathrm{KH}_{2} \mathrm{PO}_{4}, 1.2 \mathrm{MgSO}_{4}+7 \mathrm{H}_{2} \mathrm{O}, 1.8 \mathrm{CaCl}_{2}+2 \mathrm{H}_{2} \mathrm{O}$ ) containing BDM (30 mmol/l $\mathrm{C}_{4} \mathrm{H}_{2} \mathrm{NO}_{2}$ Butanedione-Monoxime) as an ATP-sensitive potassium-channel inhibitor. In the laboratory, the tissue was placed in a dish, filled with a special ice-cooled $\left(4^{\circ} \mathrm{C}\right)$ preparation solution [contents $(\mathrm{mM}): \mathrm{C}_{3} \mathrm{H}_{4} \mathrm{~N}_{2} 68.08, \mathrm{NaN}_{3}$ 65.01; $\mathrm{C}_{14} \mathrm{H}_{24} \mathrm{~N}_{2} \mathrm{O}_{10} 380.4 ; \mathrm{C}_{4} \mathrm{H}_{10} \mathrm{O}_{2} \mathrm{~S}_{2}$. 154.3; $\mathrm{MgCl}_{2} \times 6 \mathrm{H}_{2} \mathrm{O}$ 203.3; $\mathrm{C}_{10} \mathrm{H}_{14} \mathrm{~N}_{5} \mathrm{O}_{13} \mathrm{P}_{3} \mathrm{Na}_{2}$ 605.2]. The muscle bundles were resected out of the auricle and placed in a test tube containing the modified preparation solution with $1 \%$ Triton X-100 to permeabilise the membrane of the fibres for $24 \mathrm{~h}$ at $4^{\circ} \mathrm{C}$ on a shaking device. The purpose of these preparatory steps was to remove the membrane-dependent properties (skinning). After this skinning process, the RA muscle bundles were transferred to a separate ice-cooled $\left(4^{\circ} \mathrm{C}\right)$ dish again, filled with preparation solution to prepare the single RA muscle stripes (size of 2-2.5 $\mathrm{mm}$ x $0.3 \mathrm{~mm}$ ) under the microscope (x10, magnification, Leica S6D stereomicroscope; Leica Microsystems $\mathrm{GmbH}$, Wetzlar, Germany).

$R A$ pCalforce measurements. A muscle investigation system (Gradient Program; Scientific Instruments, Heidelberg, Germany) was used to expose the RA fibres to a gradual increase in the calcium concentration for force measurements. The RA fibres were fixed in the perfusion
Table I. Patients' demographics and characteristics.

\begin{tabular}{lccc}
\hline Variable & $\begin{array}{c}\text { CABG group } \\
(\mathrm{n} 48)\end{array}$ & $\begin{array}{c}\text { AVR group } \\
(\mathrm{n} 22)\end{array}$ & P-value \\
\hline Age (years) & $65.3 \pm 5.2$ & $63.7 \pm 3.5$ & 0.9 \\
Height $(\mathrm{cm})$ & $168 \pm 9.6$ & $171 \pm 13$ & 0.9 \\
BMI & $27.6 \pm 4.8$ & $26.3 \pm 6.7$ & 0.8 \\
Female gender; & & & \\
n (\%) & $23(47.9)$ & $11(50)$ & 0.7 \\
DM; n (\%) & $29(60)$ & $8(36)$ & 0.03 \\
Art. Hypertension; & & & \\
n $(\%)$ & $8(53)$ & $5(50)$ & 0.9 \\
NYHA class III-IV; & & & \\
n $(\%)$ & $21(43)$ & $6(27)$ & 0.03 \\
LVEF (\%) & $53.7 \pm 2.5$ & $55.3 \pm 4.1$ & 0.7 \\
& & &
\end{tabular}

BMI, body mass index; DM, diabetes mellitus; NYHA, New York Heart Association; LVEF, left ventricular ejection fraction.

Table II. Differences between the CABG and AVR groups.

\begin{tabular}{lccc}
\hline Variable & CABG & AVR & P-value \\
\hline F mean $(\mathrm{mN})$ & $1.51 \pm 0.14$ & $2.00 \pm 0.22$ & 0.03 \\
F max $(\mathrm{mN})$ & $2.28 \pm 0.19$ & $2.68 \pm 0.24$ & 0.02 \\
BMI <25 F max & $2.35 \pm 0.34$ & $2.89 \pm 0.57$ & 0.07 \\
BMI >25 F max & $2.43 \pm 0.40$ & $2.75 \pm 0.31$ & 0.08 \\
BMI >30 F max & $2.06 \pm 0.48$ & $2.41 \pm 0.58$ & 0.02 \\
\hline
\end{tabular}

CABG, coronary artery bypass grafting; AVR, aortic valve replacement; BMI, body mass index.

chamber and incubated with a relaxation solution [contents (mM): $\mathrm{C}_{3} \mathrm{H}_{4} \mathrm{~N}_{2}$ 68.08; $\mathrm{C}_{4} \mathrm{H}_{8} \mathrm{~N}_{3} \mathrm{O}_{5} \mathrm{PNa}_{2}+4 \mathrm{H}_{2} \mathrm{O} 327.2 ; \mathrm{NaN}_{3}$ 65.01, $\mathrm{C}_{14} \mathrm{H}_{24} \mathrm{~N}_{2} \mathrm{O}_{10}$ 380.4, $\mathrm{MgCl}_{2}$ 203.3; $\mathrm{C}_{4} \mathrm{H}_{10} \mathrm{O}_{2} \mathrm{~S}_{2}$.154.2; $\mathrm{C}_{10} \mathrm{H}_{14} \mathrm{~N}_{5} \mathrm{O}_{13} \mathrm{P}_{3} \mathrm{Na}_{2}$ 605.2; creatine kinase $400 \mathrm{U} / \mathrm{ml}$. By adding $\mathrm{CaCl}_{2}(147.02 \mathrm{mM})$ to the relaxation solution, a pCa-force curve was created. $\mathrm{pCa}$ is the negative decadic log of the calcium concentration. Specially designed software (Gradient Program; Scientific Instruments) was used to calculate the necessary amount of calcium to achieve a stepwise increase in the calcium concentration according to an equation proposed by Fabiato and Fabiato (8). The $\mathrm{pCa}$ starts with $6.5 \leq 4.0$ in 0.5 increments. For each patient, a set of three RA fibres underwent calcium-induced force measurements. The mean of these 3 measurements was determined.

\section{Results}

The mean and maximum force values of patients undergoing AVR were significantly higher than the force values of patients undergoing $\mathrm{CABG}$ ( $\mathrm{F}$ mean $2.00 \pm 0.22$ vs. $1.51 \pm 0.14 \mathrm{mN}$, $\mathrm{P}=0.03$, F $\max 2.68 \pm 0.24$ vs. $2.28 \pm 0.19 \mathrm{mN}, \mathrm{P}=0.02$; Table II). 
Table III. Summary of results.

\begin{tabular}{lrcrc}
\hline & \multicolumn{1}{c}{ BMI } & F mean $(\mathrm{mN})$ & F max $(\mathrm{mN})$ & P-value \\
\hline AVR & $<25$ vs. $>25$ & $2.18 \pm 0.1$ vs. $2.07 \pm 0.2$ & $2.89 \pm 0.31$ vs $2.75 \pm 0.26$ & 0.08 \\
& $<25$ vs. $>30$ & $2.18 \pm 0.1$ vs. $1.74 \pm 0.18$ & $2.89 \pm 0.31$ vs. $2.41 \pm 0.32$ & 0.02 \\
& $25-30$ vs. $>30$ & $2.07 \pm 0.2$ vs. $1.74 \pm 0.18$ & $2.75 \pm 0.26$ vs. $2.41 \pm 0.32$ & 0.007 \\
CABG & $<25$ vs. $>25$ & $1.50 \pm 0.42$ vs. $1.66 \pm 0.51$ & $2.34 \pm 0.26$ vs. $2.43 \pm 0.2$ & 0.19 \\
& $<25$ vs. $>30$ & $1.50 \pm 0.42$ vs. $1.36 \pm 0.3$ & $2.34 \pm 0.26$ vs. $2.06 \pm 0.2$ & 0.01 \\
& $25-30$ vs. $>30$ & $1.66 \pm 0.51$ vs. $1.36 \pm 0.3$ & $2.43 \pm 0.29$ vs. $2.06 \pm 0.2$ & 0.04 \\
\hline
\end{tabular}

CABG, coronary artery bypass grafting; VR, aortic valve replacement; BMI, body mass index.

Regarding the differentiation of BMI indices, there were significant differences in the group BMI $>30$ among

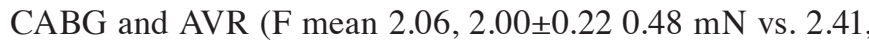
$2.00 \pm 0.22,0.58 \mathrm{mN}, \mathrm{P}=0.02)$. The $\mathrm{BMI}$ group $<25$ did not significantly differ from the BMI group 25-30 in the $\mathrm{F}$ mean and $\mathrm{F}$ max.

We divided the group after aortic valve replacement and coronary bypass grafting: in the AVR group, the highest mean and maximum forces were achieved by the patients with a BMI $<25$ (F mean $2.18 \pm 0.1 \mathrm{mN}$ vs. F $\max 2.89 \pm 0.31 \mathrm{mN}$ ). The lowest force values were developed by patients with a BMI $>30$ (F mean $1.74 \pm 0.18 \mathrm{mN}$ and $\mathrm{F}$ max $2.41 \pm 0.32 \mathrm{mN}$ ). Patients with a BMI 25-30 were in the middle between the two groups (F mean $2.07 \pm 0.2 \mathrm{mN}, \mathrm{F} \max 2.75 \pm 0.26 \mathrm{mN}$ ). When comparing the mean and maximum force values among the AVR group, we found significant differences in the force development between the BMI group $<25 \mathrm{vs}$. $>30$. This was valid for the mean forces $(2.18 \pm 0.1$ vs. $1.74 \pm 0.18 \mathrm{mN}, \mathrm{P}=0.02)$ as well as for the maximum forces $(2.89 \pm 0.31$ vs. $2.41 \pm 0.32 \mathrm{mN}$, $\mathrm{P}=0.02)$. Similar differences were evident when comparing the force values of patients with a BMI 25-30 vs. $>30$ (F mean $2.07 \pm 0.2$ vs. $1.74 \pm 0.18 \mathrm{mN}, \mathrm{F} \max 2.75 \pm 0.26$ vs. $2.41 \pm 0.32 \mathrm{mN}$, $\mathrm{P}=0.007$; Table III).

In the CABG group, the highest force values were obtained in the BMI group 25-30 ( $\mathrm{F}$ mean $1.66 \pm 0.51 \mathrm{mN}, \mathrm{F}$ max $2.43 \pm 0.29 \mathrm{mN})$ and the lowest force values again in the BMI group $>30$ (F mean $1.36 \pm 0.3 \mathrm{mN}, \mathrm{F} \max 2.06 \pm 0.2 \mathrm{mN})$.

When we compared the different BMI groups within the AVR and CABG group, we identified similar results: in both groups, significant differences were found between the BMI group <25 vs. $>30$ as well as $25-30$ vs. $>30$ : AVR: BMI <25 vs. $>30$ : F mean 2.180 .1 vs. $1.74 \pm 0.18$ and $\mathrm{F} \max 2.89 \pm 0.31$ vs. $2.41 \pm 0.32, \mathrm{P}=0.02$ and $\mathrm{BMI}$ $25-30$ vs. $>30$ : $F$ mean $2.07 \pm 0.2$ vs. $1.74 \pm 0.18$ and $F \max$ $2.75 \pm 0.26$ vs. $2.41 \pm 0.32, \mathrm{P}=0.007)$. In the $\mathrm{CABG}$ group, the following values were found: CABG: BMI 25 vs. $>30$ : F mean $1.50 \pm 0.42$ vs. $1.36 \pm 0.3$ and $F \max 2.34 \pm 0.26$ vs. $2.06 \pm 0.2$ $\mathrm{P}=0.01)$ and BMI $25-30$ vs. $>30$ : F mean $1.66 \pm 0.51$ vs. $1.36 \pm 0.3$, $\mathrm{F} \max 2.43 \pm 0.29$ vs. $2.06 \pm 0.2, \mathrm{P}=0.04)$.

Regarding the clinical characteristics of the patients, we observed significantly more patients with diabetes in the CABG group $(\mathrm{P}=0.03)$ and more New York Heart Association (NYHA) class II-IV in the CABG group $(\mathrm{P}=0.03)$. The remaining clinical features were similarly distributed in the two groups.

\section{Discussion}

The present study has shown that patients with a BMI $>30$ develop significant lower forces compared to patients with a BMI between 25-30 and $<25$. This was similar in the AVR group as well as the CABG group. These experimental observations are in concert with the literature: Adipocyte secretory products, identified as fatty acid-binding proteins (FABPs), acutely inhibited cardiomyocyte contraction in a rat model $(9,10)$. Lamounier-Zepter furthermore observed that FABP4 concentrations correlated with cardiodepressant activity in the adipocyte-conditioned medium (10).

These results can also be seen in diabetic animal studies (11) as well as skinned fibre models (12). In the CABG group, we had more diabetic patients, which may have also influenced the observed reduced force values in patients with a BMI $>30$. Diabetes seems to reduce even more contractile force in humans as well as in animals. We observed this difference to be more pronounced in patients undergoing AVR, as previously identified (13).

Additionally, during the post-surgical procedure, we found more patients in the CABG group with diabetes and with NYHA III/IV. Since the Framingham study revealed that the risk of developing heart failure was independent of diabetes in overweight and obese patients, diabetes may have an additive effect on myocardial function (14), i.e., the impairment of myocardial function in obese patients may be explained by the cardiac effects of comorbidities secondary to obesity, but they may not completely explain the obesity-associated impairment of heart function (5).

In addition, the reduced cardiac status of the patients, indicated by NYHA III/IV, may aggravate the results, as studies have shown a reduced myofilament function of skinned fibres in the experimental models of impaired heart function (15). Thus, the reduced force values observed in the CABG group may also be influenced by this function.

The observation of different force values of AVR and CABG patients may also reflect the different pathological mechanisms since aortic valve diseases are an example of pressure overload and lead to different changes in the contractile properties than ischemic heart disease (16). There is some evidence in the literature that human myocardium can better tolerate pressure overload than ischemic heart disease: during acute myocardial ischemia, the sensitivity of the myofilaments to activating $\mathrm{Ca}^{2+}$ is significantly reduced, largely 
due to the effects of intracellular acidosis on the contractile machinery (17). Previous findings of a pressure-overload rat model showed that myocytes can withstand the ultrastructural changes in pressure overload preserving $\mathrm{Ca}^{2+}$ signalling and contractility (18). That finding may be one explanation for the higher force values in patients with aortic valve disease compared to the CABG group. The issue of a potential influence of underlying disease in skinned human fibers cannot be excluded. Previous findings suggested that skinned human fibers from dilated cardiomyopathy are significantly more sensitive for calcium compared to those taken from patients with coronary or ischemic heart disease or mitral valve disease (19). Thus, we excluded this potential influence by skinning the fibers and removing all membrane-dependent processes. Regarding the transferability of results taken from atrial tissue to ventricular tissue, the literature reports higher maximal forces taken from rat ventricular fibers compared to those from atria, but considering that calcium sensitivity is species-dependent, it is also difficult to transfer this observation to human tissue (20). Another study gives some evidence that adult atrial tissue exhibits contractile properties similar to adult ventricular properties and differs from adult ventricle mainly in metabolic properties (21). So we believe to transfer these results were transferred to ventricular tissue always considering the origin of the fibers.

The present study is an attempt to examine the impact of diabetes on myofilament function in human tissue. Although the reduced contractile force values may have been influenced by several factors including the underlying pathology (aortic valve disease vs. ischemic heart disease) or the NYHA status, it is likely that altered myofilament function is present in obese patients.

Notably, the mechanisms that affect myofilament function in association with diabetes cannot be definitively estimated in the present study, but according to the literature obesity affects the myofilament function in a membrane-independent manner, as shown in our skinned fibre model.

Further studies are necessary to evaluate whether the observed reduced myofilament function may have clinical relevance since LV function was preserved in the examined patients. Additionally, studies suggest a relationship between obesity-associated dysfunctional adipose tissue and heart failure with a preserved ejection fraction (22).

\section{Acknowledgements}

The present study was funded by the German research Foudnation (DFG) and the University of Wuerzburg in the funding programme Open Access.

\section{References}

1. Braun N, Gomes F and Schütz P: 'The obesity paradox' in disease - is the protective effect of obesity true? Swiss Med Wkly. 2015 Dec 28;145:w14265. doi: http://dx.doi. org/10.4414/smw.2015.14265. eCollection 2015.

2. Mourmoura E, Chaté V, Couturier K, Laillet B, Vial G, Rigaudiere JP, Morio B, Malpuech-Brugère C, Azarnoush K and Demaison L: Body adiposity dictates different mechanisms of increased coronary reactivity related to improved in vivo cardiac function. Cardiovasc Diabetol 13: 54, 2014.
3. Tiwari S and Ndisang JF: The role of obesity in cardiomyopathy and nephropathy. Curr Pharm Des 20: 1409-1417, 2014.

4. Di Bello V,SantiniF,DiCori A,Pucci A,Palagi C,Delle Donne MG, Fierabracci P, Marsili A, Talini E, Giannetti M, et al: Obesity cardiomyopathy: is it a reality? An ultrasonic tissue characterization study. J Am Soc Echocardiogr 19: 1063-1071, 2006.

5. Lamounier-Zepter V, Ehrhart-Bornstein M, Karczewski P, Haase H, Bornstein SR and Morano I: Human adipocytes attenuate cardiomyocyte contraction: Characterization of an adipocyte-derived negative inotropic activity. FASEB J 20: 1653-1659, 2006

6. Look C, Morano I and Lamounier-Zepter V: Human adipocyte-derived factors directly inhibit cardiac contraction. J Muscle Res Cell Motil 29: 181-184, 2008.

7. Nickola MW, Wold LE, Colligan PB, Wang GJ, Samson WK and Ren J: Leptin attenuates cardiac contraction in rat ventricular myocytes. Role of NO. Hypertension 36: 501-505, 2000.

8. Fabiato A and Fabiato F: Excitation-contraction coupling of isolated cardiac fibers with disrupted or closed sarcolemmas. Calcium-dependent cyclic and tonic contractions. Circ Res 31: 293-307, 1972.

9. Kenchaiah S, Evans JC, Levy D, Wilson PW, Benjamin EJ, Larson MG, Kannel WB and Vasan RS: Obesity and the risk of heart failure. N Engl J Med 347: 305-313, 2002.

10. Lamounier-Zepter V, Look C, Alvarez J, Christ T, Ravens U, Schunck WH, Ehrhart-Bornstein M, Bornstein SR and Morano I: Adipocyte fatty acid-binding protein suppresses cardiomyocyte contraction: a new link between obesity and heart disease. Circ Res 105: 326-334, 2009

11. Satoh N and Kitada Y: Effects of MCC-135 on $\mathrm{Ca}^{2+}$ uptake by sarcoplasmic reticulum and myofilament sensitivity to $\mathrm{Ca}^{2+}$ in isolated ventricular muscles of rats with diabetic cardiomyopathy. Mol Cell Biochem 249: 45-51, 2003.

12. Akella AB, Ding XL, Cheng R and Gulati J: Diminished $\mathrm{Ca}^{2+}$ sensitivity of skinned cardiac muscle contractility coincident with troponin T-band shifts in the diabetic rat. Circ Res 76: 600-606, 1995.

13. Bening C, Weiler $\mathrm{H}$ and Vahl CF: Effects of gender, ejection fraction and weight on cardiac force development in patients undergoing cardiac surgery - an experimental examination. J Cardiothorac Surg 8: 214, 2013.

14. Lauer MS, Anderson KM, Kannel WB and Levy D: The impact of obesity on left ventricular mass and geometry. The Framingham Heart Study. JAMA 266: 231-236, 1991.

15. Belin RJ, Sumandea MP, Sievert GA, Harvey LA, Geenen DL, Solaro RJ and de Tombe PP: Interventricular differences in myofilament function in experimental congestive heart failure. Pflugers Arch 462: 795-809, 2011.

16. Huang Y and Li YX: $\mathrm{Ca}^{2+}$ sensitivity of contractile system and $\mathrm{Ca}^{2+}$ release from sarcoplasmic reticulum in skinned myocardium from rats with pressure overload LV hypertrophy and heart failure. Acta Pharmacol Sin 20: 861-864, 1999.

17. Day SM, Westfall MV and Metzger JM: Tuning cardiac performance in ischemic heart disease and failure by modulating myofilament function. J Mol Med (Berl) 85: 911-921, 2007.

18. Pérez-Treviño P, Pérez-Treviño J, Borja-Villa C, García N and Altamirano J: Changes in t-tubules and sarcoplasmic reticulum in ventricular myocytes in early cardiac hypertrophy in a pressure overload rat model. Cell Physiol Biochem 37: 1329-1344, 2015.

19. Wankerl M, Böhm M, Morano I, Rüegg JC, Eichhorn M and Erdmann E: Calcium sensitivity and myosin light chain pattern of atrial and ventricular skinned cardiac fibers from patients with various kinds of cardiac disease. J Mol Cell Cardiol 22: 1425-1438, 1990.

20. Morano I, Arndt H, Gärtner C and Rüegg JC: Skinned fibers of human atrium and ventricle: myosin isoenzymes and contractility. Circ Res 62: 632-639, 1988.

21. Vannier C, Veksler V, Mekhfi H, Mateo P and Ventura-Clapier R: Functional tissue and developmental specificities of myofibrils and mitochondria in cardiac muscle. Can J Physiol Pharmacol 74: 23-31, 1996.

22. Valero-Muñoz M,Li S, Wilson RM, Hulsmans M, Aprahamian T, Fuster JJ, Nahrendorf M, Scherer PE and Sam F: Heart failure with preserved ejection fraction induces beiging in adipose tissue. Circ Heart Fail 9: e002724, 2016. 